\title{
Analysis of Tsunami Resonance and Impact in Coastal Waters
}

\author{
† JoongWoo Lee, KyuKwang Kim*, Yoshiki Yamazaki**, \\ Kwok Fai Cheung***, Ryoichi Yamanaka**** \\ †,* Korea Maritime University, \#1 Dongsam-dong, Youngdo-gu, Busan 606-791 Korea \\ **,*** University of Hawaii at Manoa, \#2540 Dole st., Holmes 402, Honolulu, HI96822 USA \\ **** Tokushima University, \#2-24,Shinkura-cho,Tokushima ken, 770-8501 Japan
}

\begin{abstract}
Recently, extreme tsunami waves generated by submarine earthquake have caused tremendous damages to the coastal cities and ports. Strong seiche oscillations and runups are observed in specific sea areas around the world. Although no frequent impacts to the coast of Korean peninsula, there exist some important events in the east of Korea in the past. This study focuses on two historical events and recalculate with different fault and rupture mechanism for prediction considering the recent trend of submarine earthquake. The present study of the 1983 Akita tsunamis demonstrates the multi-scale resonance along continental coasts. Together with the Nankai tsunami for inland sea, we have confirmed the inland sea resonance surrounded by islands in defining the impact along the coast. Coherence and wavelet analyses for deducing a predominant period and time frequency are useful in reasoning the inundation. The resonance modes, which are largely independent of the tsunami source, allow identification of at-risk communities and infrastructure for mitigation of tsunami hazards. Furthermore, understanding of the resonance and the predicted runups for the site of power plant and industrial complex in the east coast of Korea would allow better preparation for the future disasters.
\end{abstract}

Key words : earthquake, Tsunami, fault, runup, nested grids, amplitude spectra, resonance

\section{Introduction}

Since the 2011 Tohoku-Pacific Ocean earthquake over Mw 9.0 had generated the most destructive tsunami in history in the east coast of Japan and across the Pacific, most of coastal countries are worrying about the tsunami runup disasters and exposure to radioactive contamination. Each country had started to investigate the safeness of the site and facilities and to discuss the disaster prevention media. Even the scientists and researchers, who are the expert on the tsunami prediction, are busy to investigate again the earthquake parameters and static and dynamic generation mechanism for tsunamis that had occurred already. They check all possibilities of change in terms of subfault, strike angle, slip, rupture duration, earthquake scale, and manning coefficients, etc.

The Korean peninsula is subject to tsunamis only generated from the East Sea, source of submarine earthquake near the west coast of Japan: Hokkaido and northern part of Honshu. Most of tsunamis generated by the earthquakes of Pacific Ocean rim are protected by Japan and are not reached to Korean Peninsula, except this sea. Although the history of impact of tsunamis are minor for the east coast of Korea, two strong events in 1983 and 1993 were happened and caused damages along the Korean coast, not just for port facilities but flooding due to runups along the low land coastline. On May 26, 1983, an earthquake with $7.7 \mathrm{Mw}$ occurred at $40.4 \mathrm{~N}$ and $139.1 \mathrm{E}$ in the west coast of Japan. The resulting tsunami reached the entire west coast of Japan and east coast of Russia and Korea. This had caused serious damage to near coast of Japan, Aomori, Akita and the southwestern part of Hokkaido, together with the mid-eastern coast of South Korea, Imwon. Some harbors and embayment had experienced prolonged oscillations with amplitudes.

Most of nuclear power plants in South Korea are located in the east coast, except Yonggwang plant as shown in Fig.1. The reactors of nuclear power plants are classified into 4 types such as Pressurized Water Reactor (PWR,Light), Pressurized Heavy Water Reactor (PHWR),

\footnotetext{
† Corresponding author, jwlee@hhu.ac.kr 051)410-4461, * likemark@nate.com (051)410-4981

**yoshikiy@mail.hawaii.edu, ***cheung@mail.hawaii.edu,****yamanaka@eco.tokushima-u.ac.jp

Note) This paper was presented on the subject of "Preparation for Tsunami Impact on Power Plant and Ship Navigation in the Coastal Waters" in 2011 Joint Conference KINPR proceedingsWuhan University of Technology, 3rd-5th November, 2011, pp.413-424).
} 

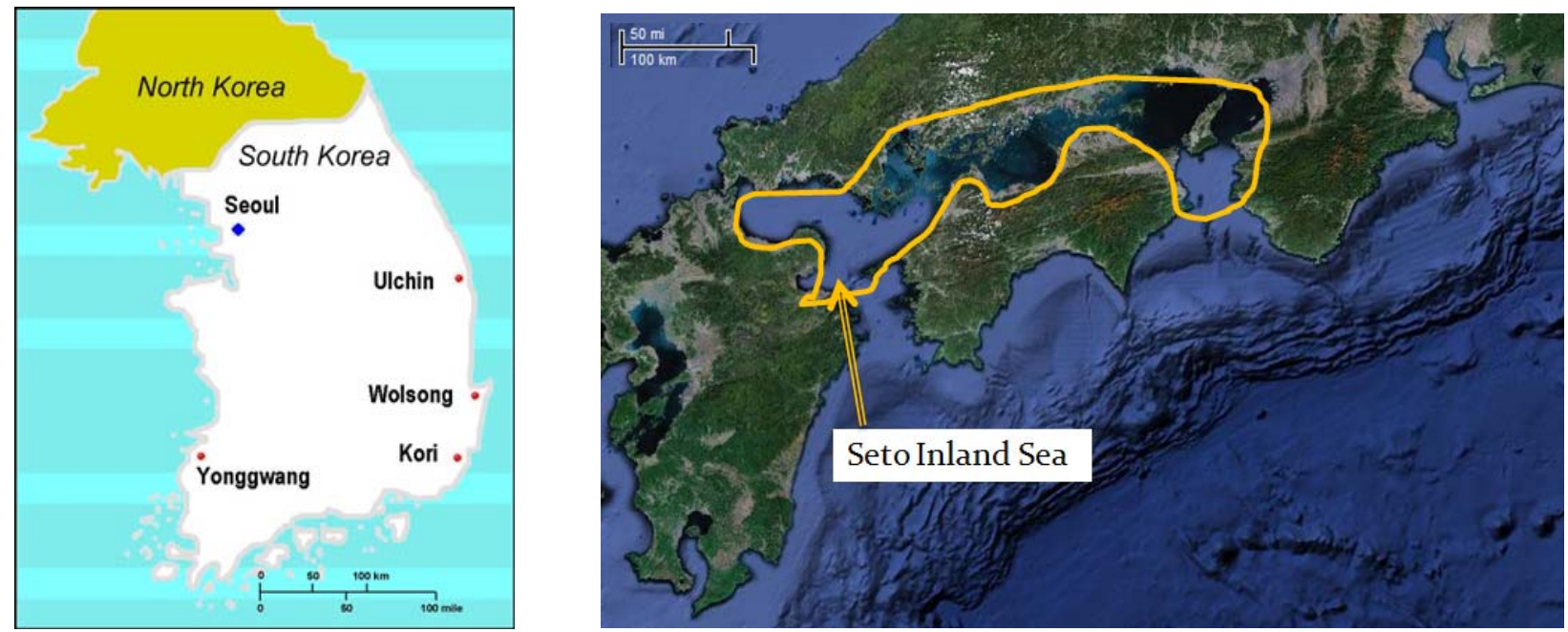

Fig. 1 Location map for the nuclear power plants in South Korea

and inland sea in Japan

Korean Standardized Nuclear Plant (KSNP), Optimized Power Reactor (OPR-1000), and Advanced Pressurized Reactor (APR-1400). Among 32 units of reactors, 26 units are located in the east coast of Korea. Besides these, there are some important industrial complex in the east coast such as POSCO Pohang Steel Company, Ulsan oil refinery, Hyundai shipbuilding and motor company, and new ports. Therefore, it is believed that investigation and recalculation on the design level for these facilities with respect to tsunami event are very important and necessary procedure.

On the other hand, tsunami impact to the inland waters causes notice to the coastal water and inland water users such as aqua-farmers, and fishery and shipping industries. One important location for inland sea is noticed to the Seto inland sea, as shown in Fig.1. It is located at the western part of Japan and surrounded by Honshu, Kyushu and Shikoku Islands. The coastal area of Shikoku Island has been frequently ravaged by huge Nankai earthquake tsunamis which had occurred along the Nankai trough. Resonance phenomena were noticed in the Seto inland sea, especially Harima-Nada area. Investigation on oscillation at inland sea due to tsunami input is also necessary for disaster prevention purpose.

\section{Governing Equations and Modeling}

In computation of far field tsunamis which travel over the ocean, the dispersion term becomes important as the long travel distance acts to disperse wave components. Yamazaki (2010) describes the governing equations for three-dimensional momentum and the continuity equations in the spherical coordinates $(\lambda, \varphi, D)$ with a radius $R$ of the earth, in which $\lambda$ is the longitude and $\varphi$ is the latitude, and $D$ is the flow depth that the distance normal to the two boundaries $D=\zeta+(h-\eta)$, where $\zeta$ is the surface elevation from the still water level, $\mathrm{h}$ is the water depth, and $\eta$ is the seafloor displacement. The depth integrated, non-hydrostatic governing equations are in the form:

$$
\begin{aligned}
& \frac{\partial U}{\partial t}+\frac{U}{R \cos \varphi} \frac{\partial U}{\partial \lambda}+\frac{V}{R} \frac{\partial U}{\partial \varphi}-\left(2 \Omega+\frac{U}{R \cos \varphi}\right) V \sin \varphi \\
& =-\frac{g}{R \cos \varphi} \frac{\partial \zeta}{\partial \lambda}-\frac{1}{2} \frac{1}{R \cos \varphi} \frac{\partial q}{\partial \lambda}-\frac{1}{2} \frac{q}{D R \cos \varphi} \frac{\partial(\zeta-h+\eta)}{\partial \lambda}-f \frac{U \sqrt{U^{2}+V^{2}}}{D} \\
& \frac{\partial V}{\partial t}+\frac{U}{R \cos \varphi} \frac{\partial V}{\partial \lambda}+\frac{V}{R} \frac{\partial V}{\partial \varphi}+\left(2 \Omega+\frac{U}{R \cos \varphi}\right) U \sin \varphi \\
& =-\frac{g}{R} \frac{\partial \zeta}{\partial \varphi}-\frac{1}{2} \frac{1}{R} \frac{\partial q}{\partial \varphi}-\frac{1}{2} \frac{q}{D R} \frac{\partial(\zeta-h+\eta)}{\partial \varphi}-f \frac{V \sqrt{U^{2}+V^{2}}}{D} \\
& \frac{\partial W}{\partial t}=\frac{q}{D} \\
& \frac{\partial(\zeta-\eta)}{\partial t}+\frac{1}{R \cos \varphi} \frac{\partial(U D)}{\partial \lambda}+\frac{1}{R \cos \varphi} \frac{\partial(V \cos \varphi D)}{\partial \varphi}=0
\end{aligned}
$$

where $U, V, W$ are the dept have raged velocity components ; $t$ is time ; $\Omega$ is the earth's angular velocity; $g$ is the gravitation acceleration ; $q$ is the non-hydrostatic pressure ; and $f$ is a dimensionless friction factor given in terms of Manning's relative roughness coefficient $n$ as $f=n^{2} g / D^{1 / 3}$.

For near field tsunamis, the Cartesian coordinate system is used because the areas included in model simulations are not wide, where effect of the earth's curvature is insignificant. Therefore, the governing equations in the spherical coordinate system can be transformed into the 
Cartesian coordinates system and the momentum and continuity equations are transformed into equations (5) through (7).

$$
\begin{aligned}
& \frac{\partial U}{\partial t}+U \frac{\partial U}{\partial x}+V \frac{\partial U}{\partial y} \\
& =-g \frac{\partial \zeta}{\partial x}-\frac{1}{2} \frac{\partial q}{\partial x}-\frac{1}{2} \frac{q}{D} \frac{\partial}{\partial x}(\zeta-h+\eta)-f \frac{U \sqrt{U^{2}+V^{2}}}{D} \\
& \frac{\partial V}{\partial t}+U \frac{\partial V}{\partial x}+V \frac{\partial V}{\partial y} \\
& =-g \frac{\partial \zeta}{\partial y}-\frac{1}{2} \frac{\partial q}{\partial y}-\frac{1}{2} \frac{q}{D} \frac{\partial}{\partial y}(\zeta-h+\eta)-f \frac{V \sqrt{U^{2}+V^{2}}}{D} \\
& \frac{\partial(\zeta-\eta)}{\partial t}+\frac{\partial(U D)}{\partial x}+\frac{\partial(V D)}{\partial y}=0
\end{aligned}
$$

The finite difference formulation utilizing the upwind flux approximation in the continuity equation as well as the advective terms in the horizontal momentum equations is adopted for the hydrostatic and non-hydrostatic components of the governing equations in both the spherical and Cartesian coordinate systems. Grid-nesting scheme for the model by Yamazaki et al. (2006) was adopted here. Model uses the Cartesian coordinate grids with the fluxes, the velocity, surface elevation as well as the non-hydrostatic pressure as input variables to a fine inner grid and the surface elevation as output to the outer grid.

\subsection{Spherical Coordinate System Model}

Spherical coordinate system model was applied to the case for 1983 Akita earthquake event, subfault 1 and 2 (Aida, 1984) as shown in Table 1, because of wide area for tsunami propagation. The numerical model reproduces the amplitude of the tsunami time series and the frequency contents in the spectrum. Fig.2 shows the location and bathymetry for the nested grid. In the center of East sea (Japan sea), there exists Daewhatoe (Yamato Rise) and it causes wave concentration to this area and scattering behind it. Fig. 3 shows the sea surface configuration right after the rupture. The main energy for the resulting tsunami propagated toward the west coast of Japan and Russia and Korean coasts. Fig.4 indicates the tsunami wave amplitude over the East sea (Japan sea) with a maximum value of $1.5 \mathrm{~m}$ over the deep ocean. The tsunami propagates away from the rupture in radial directions. The Daewhatoe refracts and traps the radiated energy initially as progressive edge waves on the shelf. The trapped waves at the coast of North Korea oscillate at the natural periods of the embayment and emit long period waves into the open ocean for several hours. Fig. 5 is the computed wave forms and spectra at Ewashi and Iwanai of Houshu, Japan. The model produces the initial positive wave and captures the distinct 60 and 100-min oscillations. The energy bands cover the natural periods of oscillation of large scale coastal bathymetric features resulting in the amplification across the Korean coast. Fig.6 shows sum of the maximum water level at the east coast of Korea for 7 hours of tsunami propagation period. More than $2 \mathrm{~m}$ of water level was shown in the mid of Korean coast.

Table 1 Subfault parameters (after Aida, 1984)

\begin{tabular}{|c|c|c|c|c|c|c|c|c|c|}
\hline $\begin{array}{c}\text { Fault } \\
\text { No. }\end{array}$ & $\begin{array}{c}\text { Lat } \\
\left({ }^{\circ} \mathrm{N}\right)\end{array}$ & $\begin{array}{c}\text { Long } \\
\left({ }^{\circ} \mathrm{E}\right)\end{array}$ & $\mathrm{d}(\mathrm{km})$ & $\boldsymbol{\theta}\left({ }^{\circ}\right)$ & $\delta\left({ }^{\circ}\right)$ & $\lambda\left({ }^{\circ}\right)$ & $\mathrm{L}(\mathrm{km})$ & $\mathrm{W}(\mathrm{km})$ & $\begin{array}{c}\text { Slip } \\
(\mathrm{m})\end{array}$ \\
\hline$(1)$ & 40.21 & 138.84 & 2 & 22 & 40 & 90 & 40 & 30 & 7.6 \\
\hline$(2)$ & 40.54 & 139.02 & 3 & 355 & 25 & 80 & 60 & 30 & 3.05 \\
\hline
\end{tabular}
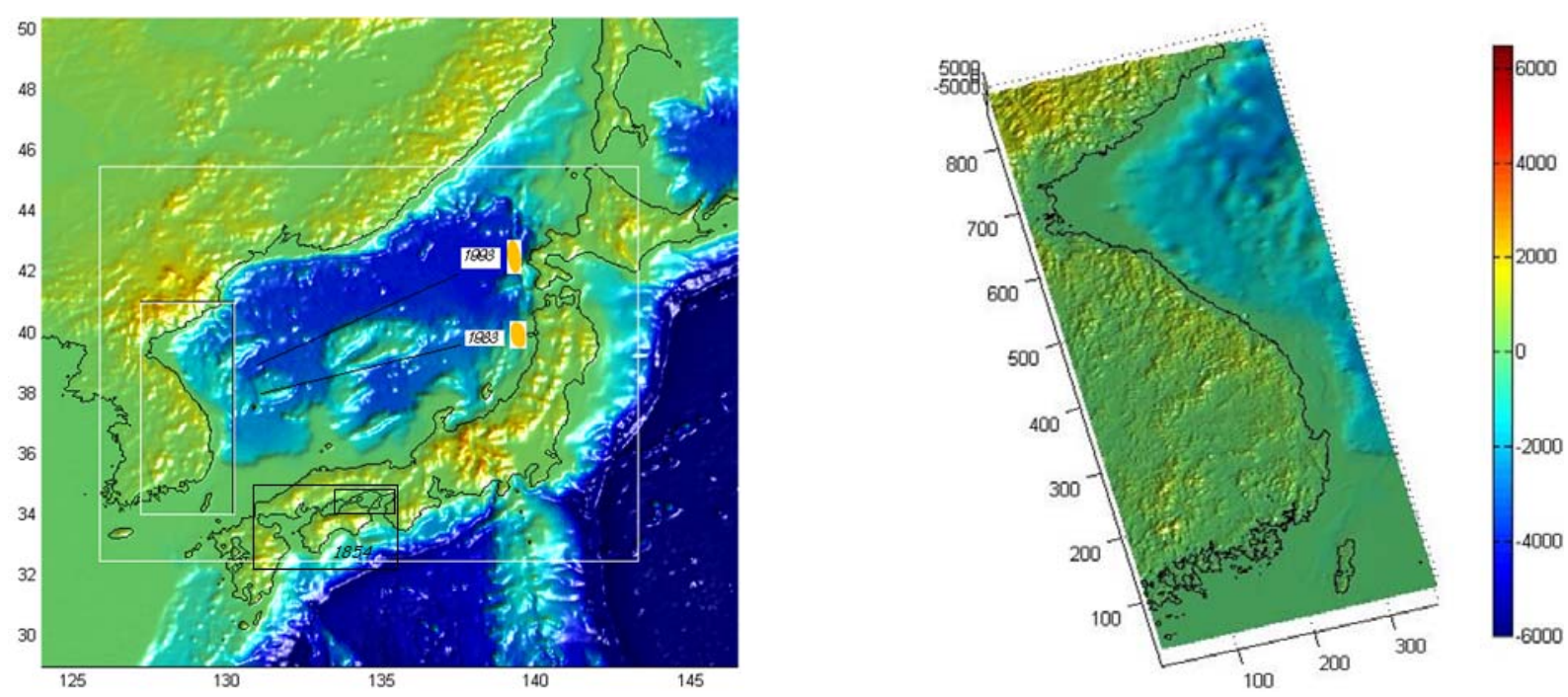

Fig. 2 Location map and topography with the nested grids 


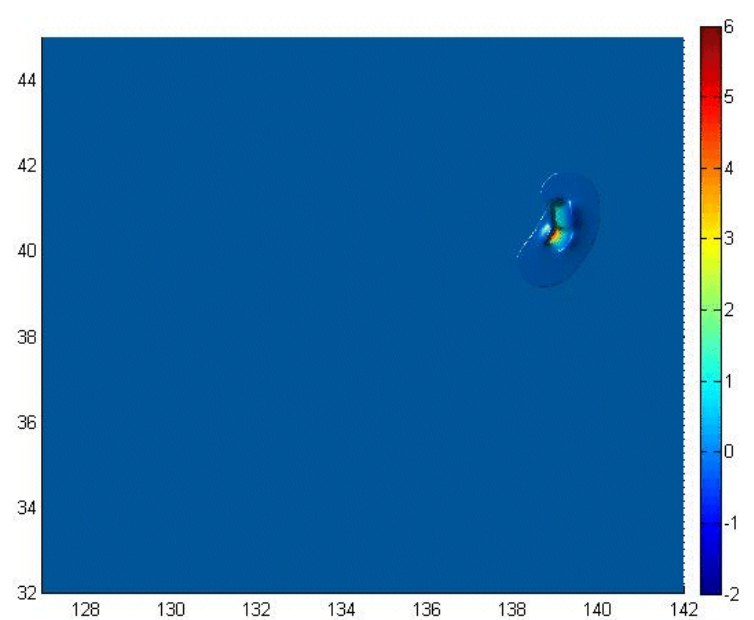

Fig. 3 Initial response of Akita earthquake in 1983

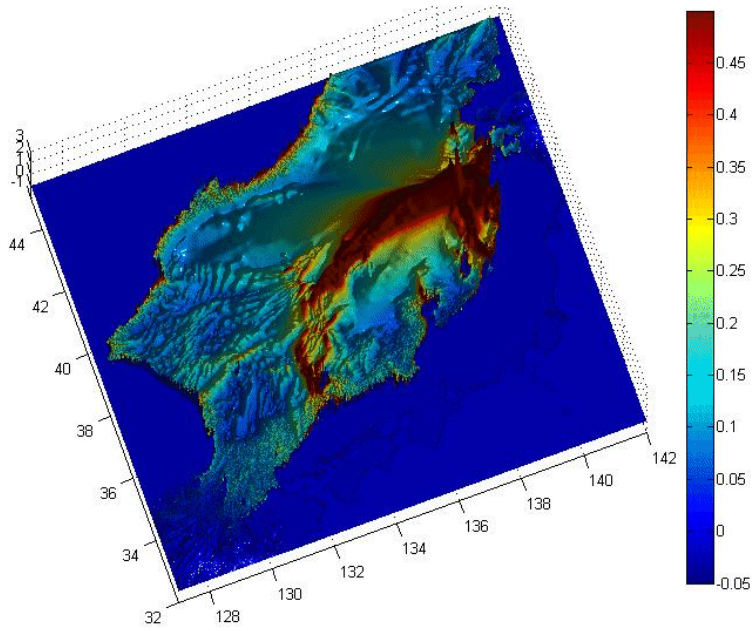

Fig. 4 Maximum responses for 1983 tsunami
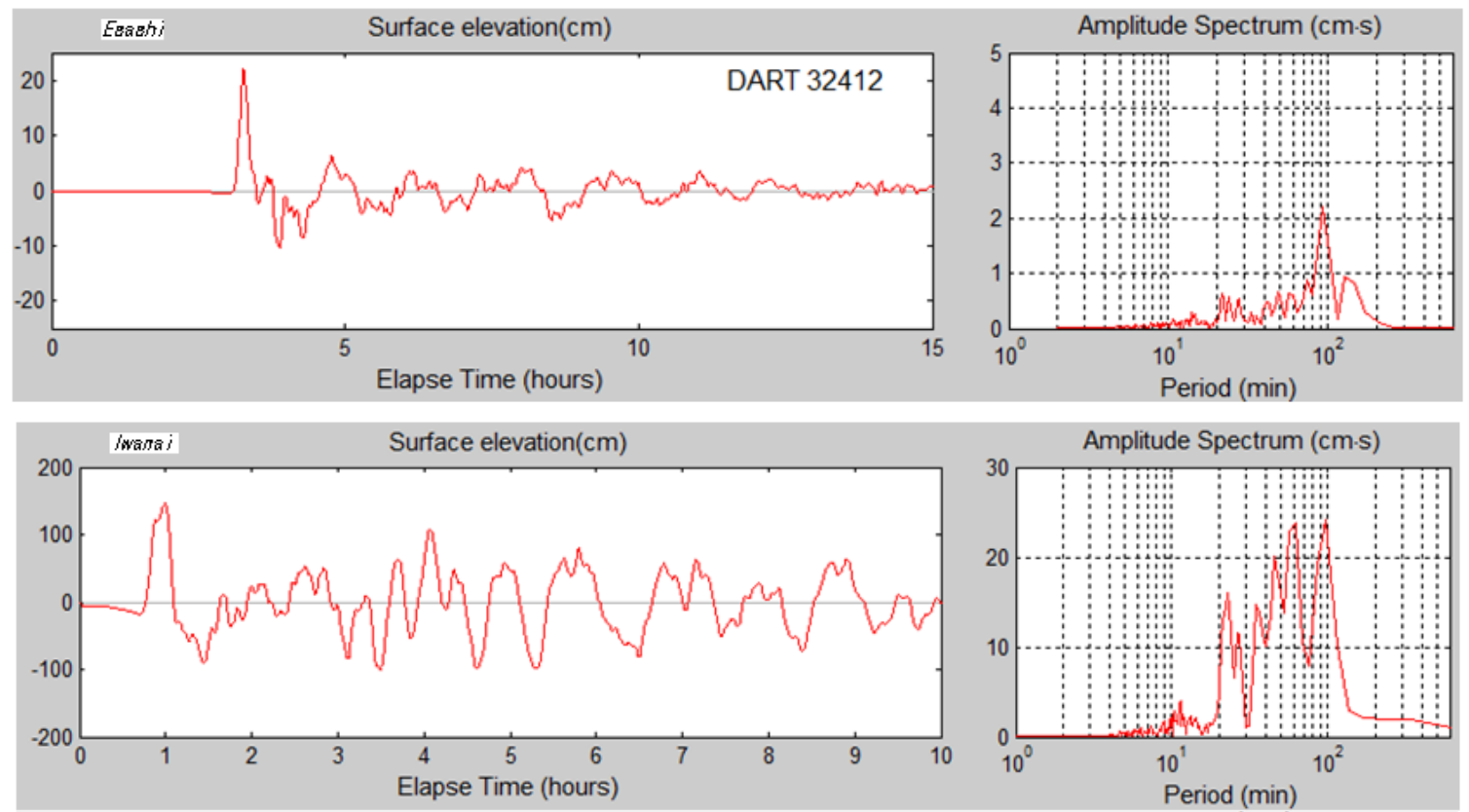

Fig. 5 Time series and spectra of surface elevation at water-level stations at Ewashi and Iwanai areas

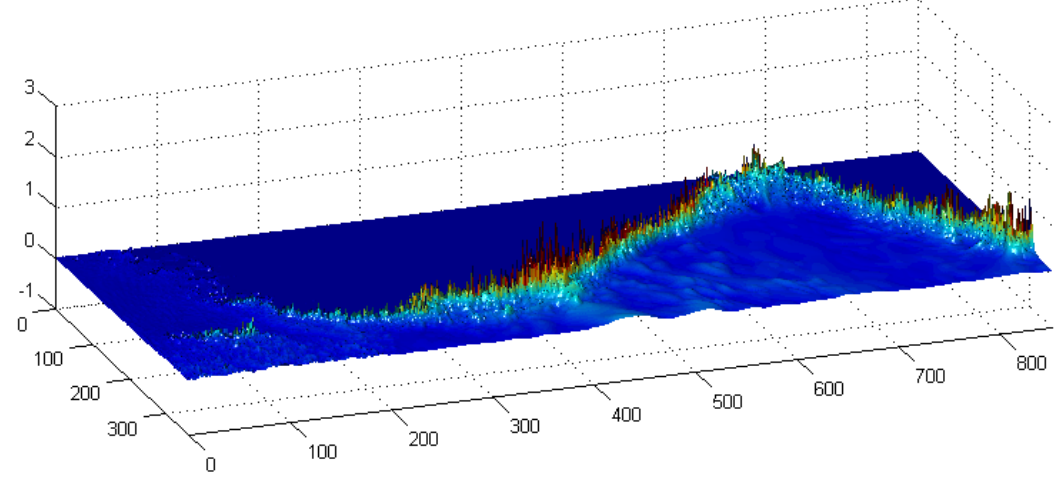

Fig. 6 Maximum water level at the east coast of Korea 


\subsection{Cartesian Coordinate System Model}

Cartesian coordinate system model was applied to thecase for the Seto inland sea because of narrow area for tsunami propagation but complicate coastal geometry. Fault model used is Aida model for 1854 Ansei Nankai earthquake Mw 8.4, calibrated using observed data (Aida, 1981) as shown in Table 2.

Fig. 7 shows past Nankai eqrthquake epicenter locations. Two nested grids were used for Cartesian coordinate system model as shown in Fig.2 (black line). Fig.8 shows the model result that Tsunami waves propagate through narrow channels which located eastern and western end of the sea and wave characteristics were changed by complex topography. From simulation result, tsunami height in the Seto inland sea was less than $1 \mathrm{~m}$, except Osaka bay and Harima-nada sea areas. Wave period of $50 \mathrm{~min}$ was propagated from western strait and passed through the Seto inland sea. At some time later, wave period of $50 \mathrm{~min}$ also propagated eastern strait, encountered the wave from western and passed through the Seto inland sea. However, latest researches pointed out that maximum tsunami height in Seto inland sea would appear more than 10 hours after tsunami occurrence by multiple reflected waves caused by topographical feature, enclosed and complex shoreline. This means that multiple amplification of tsunami wave and local drastic fluctuation might occur in inland sea area.

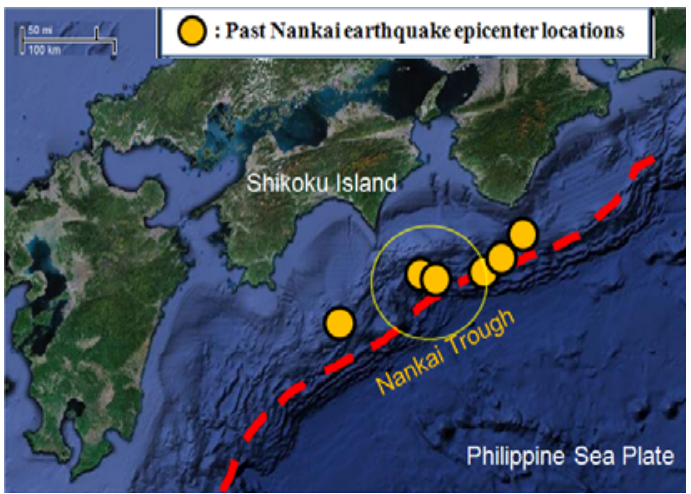

Fig. 7 Location of epicenter Nankai earthquakes

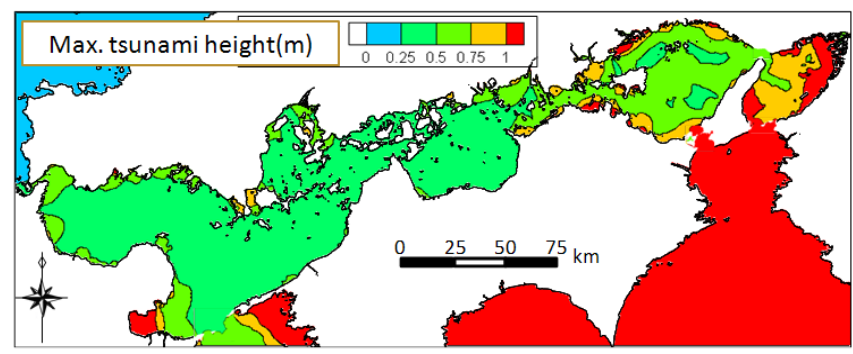

Fig. 8 Maximum tsunami response in the Seto inland sea
Table 2 Subfault parameters (after Aida, 1981)

\begin{tabular}{|c|c|c|c|c|c|c|c|c|c|}
\hline $\begin{array}{r}\text { Fault } \\
\text { No. }\end{array}$ & $\begin{array}{c}\text { Lat } \\
\left({ }^{\circ} \mathrm{N}\right)\end{array}$ & $\begin{array}{c}\text { Long } \\
\left({ }^{\circ} \mathrm{E}\right)\end{array}$ & $\begin{array}{c}\mathrm{d}(\mathrm{km} \\
)\end{array}$ & $\theta\left({ }^{\circ}\right)$ & $\delta\left({ }^{\circ}\right)$ & $\lambda\left({ }^{\circ}\right)$ & $\mathrm{L}(\mathrm{km})$ & $\mathrm{W}(\mathrm{km})$ & $\mathrm{U}(\mathrm{km})$ \\
\hline$(1)$ & 32.7 & 134.7 & 1 & 250 & 20 & 117 & 150 & 120 & 630 \\
\hline$(2)$ & 33.41 & 136.2 & 10 & 250 & 10 & 127 & 150 & 70 & 470 \\
\hline
\end{tabular}

\section{Resonance Analysis}

Spectral analysis of the computed surface elevation and investigation of the complex amplitude over the grid level 2 give understanding of the surface motion along the Korean coast and in the Seto inland sea as a function of oscillation period.

\subsection{Open Coast Analysis}

Resonance amplification of the 1983 Akita tsunami occurs at a number of periods associated with standing waves over the coastal slope and embayment along the Korean coast. Fig.9 shows spectral energy and peak period of the tsunami in Korean coastal waters predicted by the numerical model. Strong amplifications at Ulchin, Youngil Bay, Ulsan of South Korea, and Younghung and Hamhung Bay of North Korea are represented and the corresponding peak periods are shown in Fig.9, too. The most prominent energy concentration is over Youngil Bay of South Korea and Hamhung Bay of North Korea, where a combination of the harmonic modes of oscillation occurs. Coastal regions with high energy are located in large embayment, where the tsunami triggers the fundamental mode of oscillation. Those well studied location of basin oscillation are Kahului and Hilo Bay, Hawaii (Munger \& Cheung, 2008), Arauco Gulf,
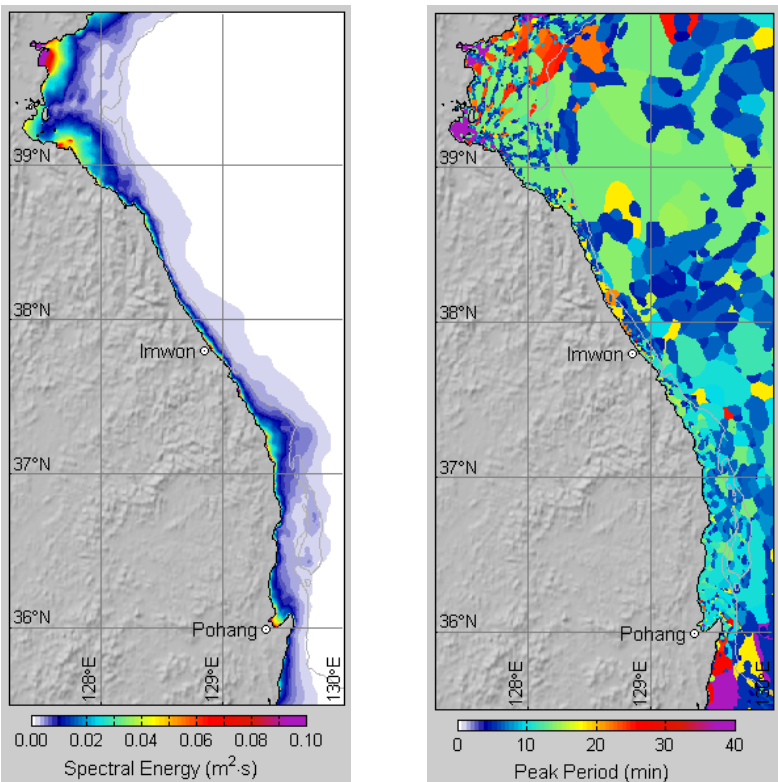

Fig. 9 Spectral energy and peak period in the east coast of Korea 


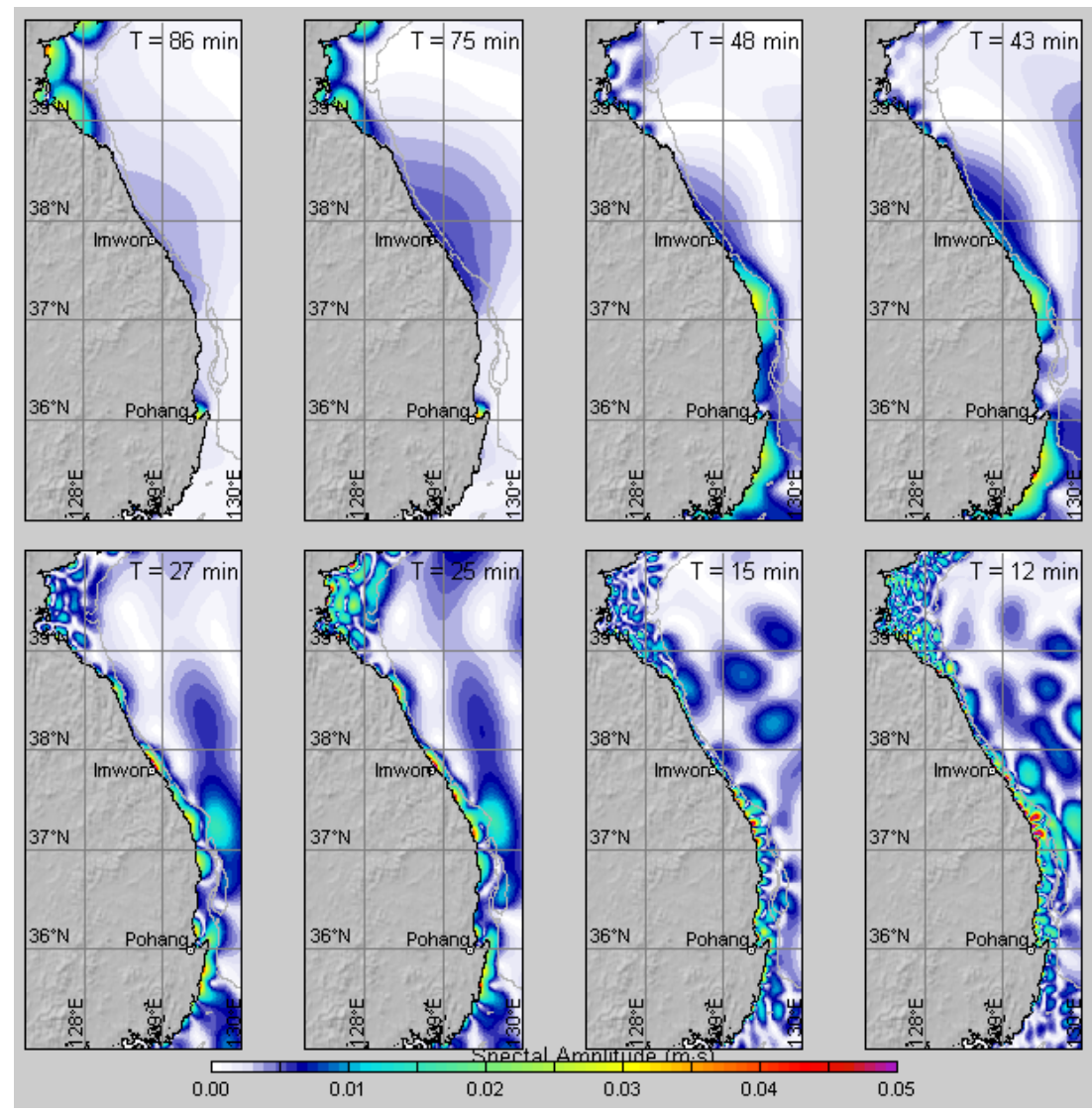

Fig. 10 Amplitude of resonance modes along the east coast of Korea
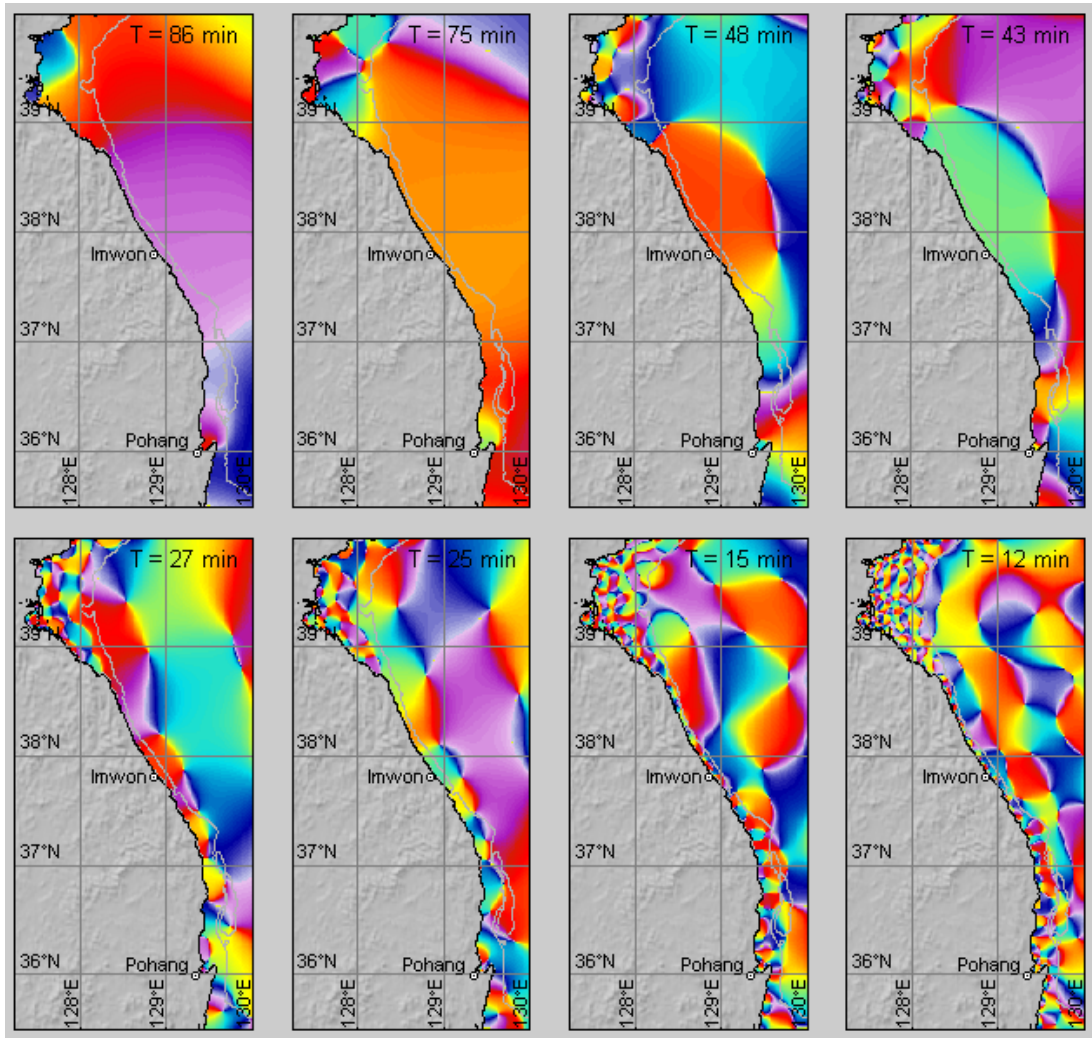

$\begin{array}{lllllllllllll}-180 & -150 & -120 & -90 & -60 & -30 & 0 & 30 & 60 & 90 & 120 & 150 & 180\end{array}$

Fig. 11 Phase angle of resonance modes along the east coast of Korea 
Chile (Yanazaki \& Cheung, 2011), and Pago Pago Harbor and Fagaitua Bay, American Samoa (Roeber et al., 2010). Rabinovich \& Monserrat (1998) made a comparative analysis of tsunami oscillations in different bays. Fig.10 and Fig.11 show the amplitude and phase of eight dominant oscillation modes between 12 to 86 min period associated with standing waves over the peninsula slope and shelf complex as well as the embayment along the east coast of Korea. The $200 \mathrm{~m}$ depth contour shows the outline of the peninsula shelf. The phase plots in Fig.11 show some of the oscillation modes contain partial standing waves. However, the nodes were not defined well, because of shelf and coast configurations. The 86min amplitude plot shows a system of standing waves, which is a coastal trapped oscillation at Younghung and Hamhung Bay of North Korea. This oscillation is prolonged to $75 \mathrm{~min}$, which is a dominant mode at Youngil Bay of South Korea. The shelf width and shoreline configuration dominate the resonant amplification with periods between 12 and $27 \mathrm{~min}$. These coastal trapped waves are the primary source of oscillations in bays, narrow shelves, and harbors observed during the tsunami.

\subsection{Inland Sea Analysis}

After the passage of tsunami wave, fluctuation of sea level continued at some points. Maximum tsunami height in the Seto inland sea appeared more than 10 hours after the time of tsunami occurrence. In order to analyze the resonance response in the inland sea, nine points at Harima-nada in Seto inland sea were selected as shown in Fig.12. Fig.13 shows the time series of sea level variation at these locations in terms of power spectrum. This is a temporal-frequency analysis method called wavelet analysis. The $\mathrm{x}^{-}$axis is the wavelet location in time(min) and the $\mathrm{y}-$ axis is the wavelet period(min). It gives a predominant wave period corresponding to the large value area by time period power spectra. The sea level was changed irregularly up to $1000 \mathrm{~min}$ but after this, the sea level continued to oscillate with opposite phase in some points. It shows different patterns depending on the location but there exists an oscillation mode of 100 min period. It is now much clearer that there is large power in the 50min and exists a oscillation mode of 100min period, which is lasting more than 1000min (Kim et al., 2011). From this result, it is considered that a seiche motion was induced in this inland sea.

In order to analyze this in the detail, we made coherence analysis for the selected stations. Selected group for coherence analysis are $\mathrm{D}^{-} \mathrm{A}, \mathrm{D}-\mathrm{E}$, and $\mathrm{D}^{-\mathrm{F}}$ as shown in Fig.14. The value of 1 for the coherence graph means that the two points coincided with each other and 0 means no coincidence between two points. A and D are some of coherence with in phase. However, D and $\mathrm{E}$ have strong
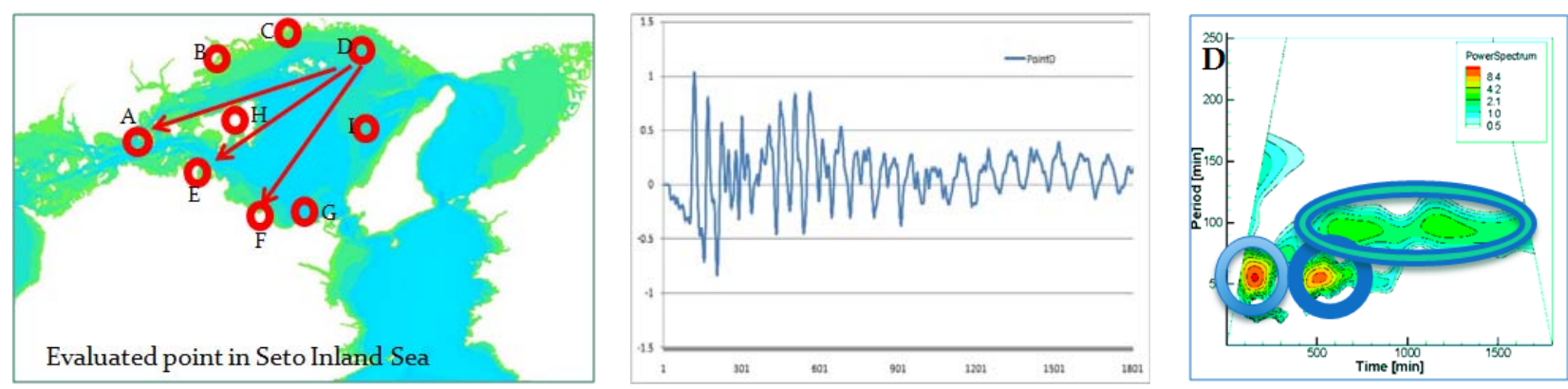

Fig. 12 Evaluation points, wave forms and variation of periods at point D
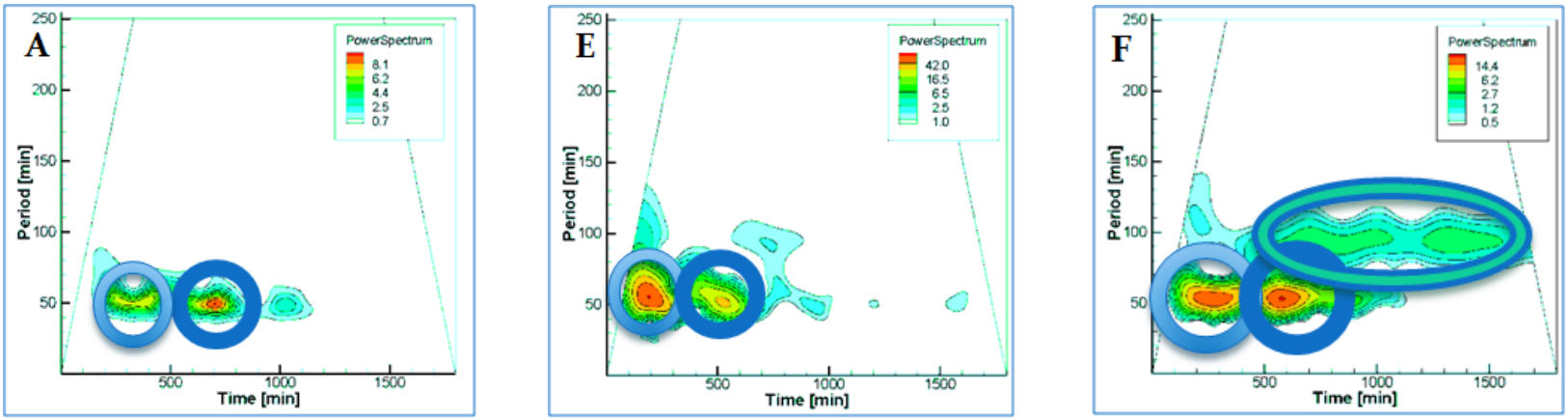

Fig. 13 Variation of wave periods at point A, E, and F, respectively 


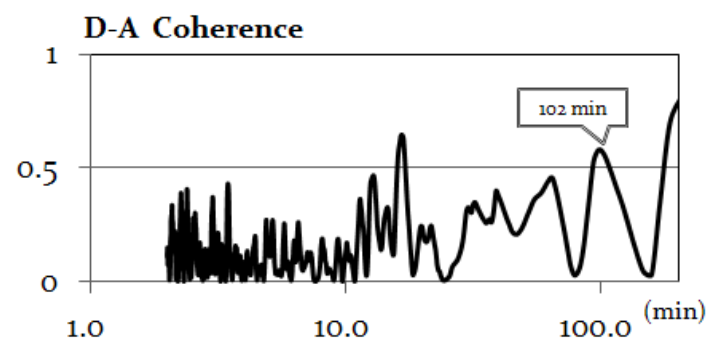

D-E Coherence

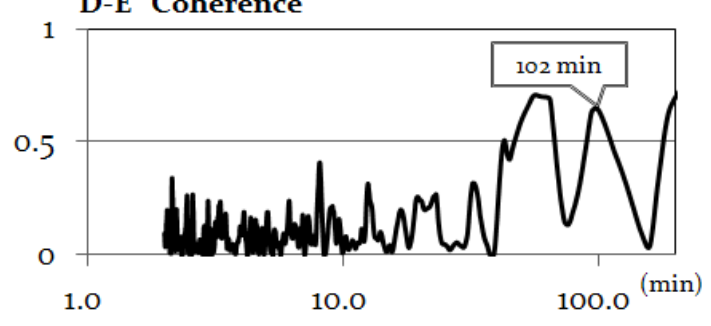

D-F Coherence

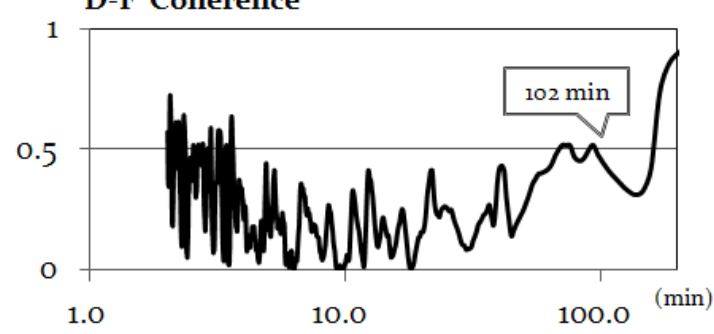

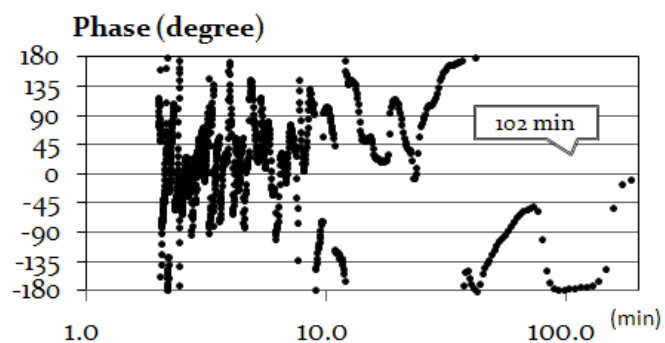
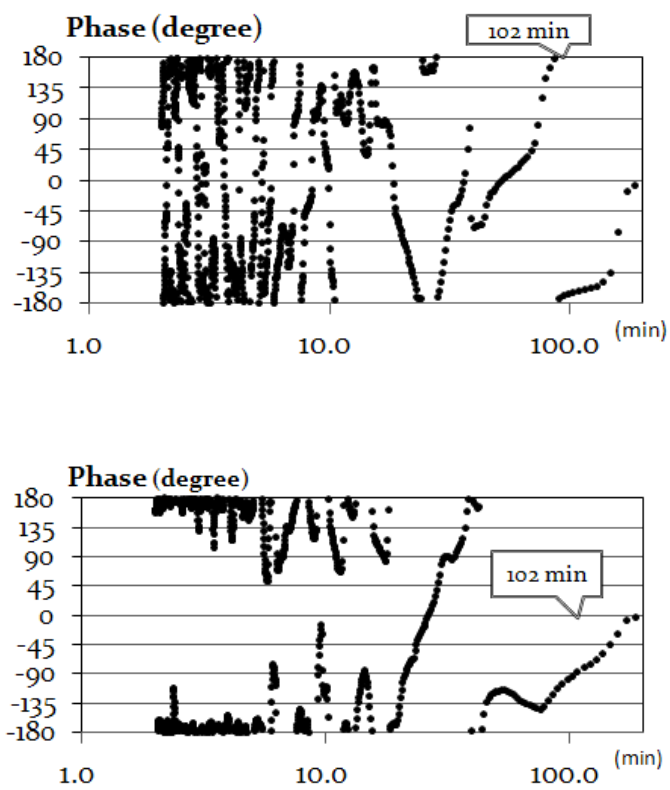

Fig. 14 Coherence analysis for period and phase

coherence but opposite position. F and D show similar pattern. This result means that tsunami wave induce tsunami resonance in the inland sea. This is the reason why the fluctuation of sea level was continued. Industrial area near this inland sea is being expanded and the use of sea transportation increases in spite of narrow seaway. Population near shore line and aqua-farming equipments moored are getting increased. Therefore, there is a possibility of occurrence of new type disaster to ship and aqua-farming equipment in inland sea.

\section{Conclusion}

The recent trend for earthquakes and tsunamis shows stronger and higher runup. For prediction of tsunami waves at the coastal cities, it is necessary to reform static and dynamic earthquake parameters. Present study with the grid-nesting scheme can model entire tsunami evolution from its generation, propagation, transformation, and runup and provide amplification pattern of tsunamis over reefs and from the coastal embayment during the 1983 Central East
Sea earthquake Tsunami. Other nested sites for industry plants would be analyzed in terms of spectra, runup, and resonance later. From the result of the inland sea tsunami analysis for 1854 Ansei Nankai earthquake, tsunami waves propagate through narrow channels which located at the eastern and western end of the sea and wave characteristics were changed by complex topography. According to wavelet analysis for the inland sea, long-term fluctuations over 100min were generated by tsunami resonance and this might cause problems on mooring ships and navigation inland sea areas.

\section{Acknowledgements}

This work is the outcome of Human Resource Development Center for Economic Region Leading Industry Project, supported by the Ministry of Education, Science \& Technology (MEST) and the National Research Foundation of Korea (NRF) and Manpower Development Program for Marine Energy by the Ministry of Land, Transport and Maritime Affairs (MLTM). The authors would like to thank 
SOEST, the University of Hawaii at Manoa and Tokushima University in terms of facilities and the strong support for this study.

\section{References}

[1] Aida, I. (1981), "Numerical Experiments for the Tsunamis Generated off the Coast of the Nankaido District", Bull. Eqrthq. Res. Inst. Univ. Tokyo, Vol.56, pp.713-730.

[2] Aida, I. (1984), "A Source Model of the Tsunami Accompanying the 1983 Nihonkai-Chubu Earthquake", Bull. Eqrthq. Res. Inst. Univ. Tokyo, Vol.59, pp.93-104.

[3] Kim, K.K., Lee, J.W., Kang, S.J., Kwon, S.H., and Lee, H.H. (2011), "Basic Study on Tsunami Disaster Mitigation for Ship Navigation in Inland Sea", 2011 Proc. of KINPR, Fall (in Korean)., Vol.2011, pp.219-220.

[4] MKE (2010), "Nuclear Power, Our Hope for Low Carbon and Green Growth", 25 $5^{\text {th }}$ Korea Atomic Industrial Forum.

[5] Munger, S. and Cheung, K.F. (2008), "Resonance in Hawaii waters from the 2006 Kuril Islands Tsunami", Geophysical Research Letters, Vol.35, L07605, pp.1-7.

[6] Rabinovich, A.B. and Monserrat, S. (1998), "Generation of Meteorological Tsunamis (Large Amplitude Seiches) near the Balearic and Kuril Islands", Natural Hazards, Vol.18, No.1, pp.27-55

[7] Roeber, V., Yamazaki, Y., and Cheung, K.F. (2010), "Resonance and impact of the 2009 Samoa Tsunami around Tutuila", American Samoa, Geophysical Research Letters, Vol.37, L21604, pp.1-8

[8] Yamazaki, Y. (2010), "Depth-integrated, Non-hydrostatic Model with Grid Nesting for Tsunami Generation, Propagation, and Runup", $\mathrm{PhD}$ Dissertation, Ocean Resources Engineering, University of Hawaii at Manoa.

[9] Yamazaki, Y. and Cheung, K.F. (2011), "Shelf resonance and Impact of near-field tsunami generated by the 2010 Chile earthquake", Geophysical Research Letters, Vol.38, L12605, pp.1-8

Received 14 November 2011

Revised 27 December 201

Accepted 27 December 2011 